$1999-11-22$

\title{
Selective excitation and thermal quenching of the yellow luminescence of GaN
}

John S. Colton

john_colton@byu.edu

P. Y. Yu

K. L. Teo

E. R. Weber

P. Perlin

See next page for additional authors

Follow this and additional works at: https://scholarsarchive.byu.edu/facpub

Part of the Astrophysics and Astronomy Commons, and the Physics Commons

\section{Original Publication Citation}

Selective excitation and thermal quenching of the yellow luminescence of GaN, J.S. Colton, K.L. Teo, P.Y. Yu, P. Perlin, E.R. Weber, I. Grzegory and K. Uchida, Appl. Phys. Lett. 75, 3273 (1999).

The original version may be found at: http://apl.aip.org/resource/1/applab/v75/i21/p3273_s1

\section{BYU ScholarsArchive Citation}

Colton, John S.; Yu, P. Y.; Teo, K. L.; Weber, E. R.; Perlin, P.; Grzegory, I.; and Uchida, K., "Selective excitation and thermal quenching of the yellow luminescence of GaN" (1999). Faculty Publications. 609.

https://scholarsarchive.byu.edu/facpub/609

This Peer-Reviewed Article is brought to you for free and open access by BYU ScholarsArchive. It has been accepted for inclusion in Faculty Publications by an authorized administrator of BYU ScholarsArchive. For more information, please contact ellen_amatangelo@byu.edu. 


\section{Authors}

John S. Colton, P. Y. Yu, K. L. Teo, E. R. Weber, P. Perlin, I. Grzegory, and K. Uchida 


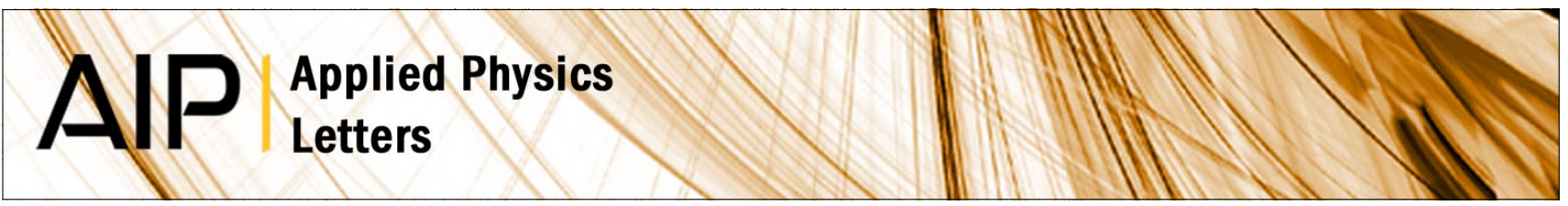

\title{
Selective excitation and thermal quenching of the yellow luminescence of GaN
}

\author{
J. S. Colton, P. Y. Yu, K. L. Teo, E. R. Weber, P. Perlin et al.
}

Citation: Appl. Phys. Lett. 75, 3273 (1999); doi: 10.1063/1.125322

View online: http://dx.doi.org/10.1063/1.125322

View Table of Contents: http://apl.aip.org/resource/1/APPLAB/v75/i21

Published by the American Institute of Physics.

\section{Related Articles}

Emission enhancement mechanism of GaN:Eu by Mg codoping J. Appl. Phys. 113, 013105 (2013)

Electronic transitions and fermi edge singularity in polar heterostructures studied by absorption and emission spectroscopy

J. Appl. Phys. 112, 123721 (2012)

Polarization-resolved resonant fluorescence of a single semiconductor quantum dot Appl. Phys. Lett. 101, 251118 (2012)

2.8 $\mu \mathrm{m}$ emission from type-I quantum wells grown on InAsxP1-x/InP metamorphic graded buffers Appl. Phys. Lett. 101, 251107 (2012)

Impact of light polarization on photoluminescence intensity and quantum efficiency in AIGaN and AllnGaN layers Appl. Phys. Lett. 101, 242102 (2012)

\section{Additional information on Appl. Phys. Lett.}

Journal Homepage: http://apl.aip.org/

Journal Information: http://apl.aip.org/about/about_the_journal

Top downloads: http://apl.aip.org/features/most_downloaded

Information for Authors: http://apl.aip.org/authors

\section{ADVERTISEMENT}

\section{AIP Applied Physics Letters}

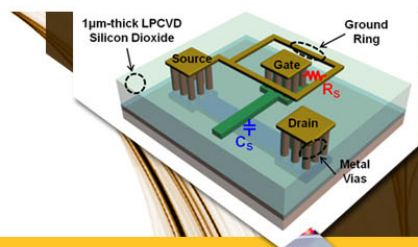

SURFACES AND INTERFACES

Focusing on physical, chemical, biological structural, optical, magnetic and electrical properties of surfaces and interfaces, and more..

\section{EXPLORE WHAT'S NEW IN APL}

SUBMIT YOUR PAPER NOW!
ENERCY CONVERSION AND STORACE 


\title{
Selective excitation and thermal quenching of the yellow luminescence of $\mathrm{GaN}$
}

\author{
J. S. Colton ${ }^{\mathrm{a})}$ and P. Y. Yu \\ Department of Physics, University of California, Berkerley, California 94720; and Materials Sciences \\ Division, Lawrence Berkeley National Laboratory, Berkeley, California 94720
}

K. L. Teo

Department of Electrical Engineering, National University of Singapore, Singapore 119260

E. R. Weber

Department of Materials Science and Mineral Engineering, University of California, Berkeley, California 94720; and Materials Science Division, Lawrence Berkeley National Laboratory, Berkeley, California 94720

P. Perlin and I. Grzegory

UNIPRESS, High Pressure Research Center, Polish Academy of Sciences, 01-142 Warsaw, Poland

\author{
K. Uchida \\ Department of Communications and Systems, The University of Electro-Communications, \\ 1-5-1 Choufugaoka, Choufu, Tokyo 182, Japan
}

(Received 6 August 1999; accepted for publication 30 September 1999)

\begin{abstract}
We report the observation of narrower structures in the yellow luminescence of bulk and thin-film $n$-type GaN, using the technique of selective excitation. These fine structures exhibit thermal quenching associated with an activated behavior. We attribute these fine structures to phonons and electronic excitations of a shallow donor-deep acceptor complex, and determine its activation energy for delocalization. Our results suggest that in addition to distant donor-acceptor pairs, the yellow luminescence can also involve emission complexes of shallow donors and deep acceptors.

(C) 1999 American Institute of Physics. [S0003-6951(99)04347-8]
\end{abstract}

Recently, GaN and related compounds have become the subject of much interest as a result of their many applications in optical displays and optical data storage. ${ }^{1}$ Room temperature GaN-based laser diodes ${ }^{2}$ and light-emitting diodes ${ }^{3}$ have become commercially available. However, many basic questions remain unanswered, such as the origin of the broadband emission centered around 2.2-2.3 eV, known as yellow luminescence (YL). Many models have been advanced to explain its origin, including transitions from shallow donor to deep acceptor, ${ }^{4-9}$ shallow donor to deep donor, ${ }^{10,11}$ and deep donor to shallow acceptor. ${ }^{12}$ Even within these competing models, there are disagreements, for example whether the YL emission comes from distant donor-acceptor pairs ${ }^{13}$ (DAPs), or from localized DAP complexes. ${ }^{14}$

The large linewidth $(\sim 0.5 \mathrm{eV})$ of the YL has made it difficult to discern features related to the microscopic structures of the defects involved. To overcome this difficulty, we have employed the technique of selective laser excitation to study YL in $n$-type GaN samples. This technique is a wellestablished method to resolve fine structures within an inhomogeneously broadened emission spectra, and has been used with many materials, including $\mathrm{ZnSe},{ }^{15} \mathrm{CdSe},{ }^{16}$ porous $\mathrm{Si}^{17}$ Ge microcrystals, ${ }^{18}$ and most recently GaInN. ${ }^{19}$

By using $\mathrm{Ar}^{+}$-ion and tunable dye lasers, we have achieved an excitation range of 2.1-2.7 eV. We have found that several narrower peaks appear within the broad YL linewidth when the YL is excited resonantly. These selectively

${ }^{a}$ Electronic mail: colton@socrates.berkeley.edu excited peaks also differ from the above band-gap-excited YL in their thermal behavior. They exhibit strong thermal quenching at temperatures above $\sim 150 \mathrm{~K}$. Our results are consistent with a model in which the YL contains contributions from donor-acceptor complexes.

Our experiment was performed on three GaN samples: a $2.65 \mu \mathrm{m}$ film grown on sapphire by metalorganic chemical vapor deposition, and two bulk samples grown under high pressure. The film was heavily doped with $\mathrm{Si}$. The carrier concentration from Hall-effect measurements was 5 $\times 10^{18} \mathrm{~cm}^{-3}$. The bulk samples also had high carrier concentrations $\left(\sim 5 \times 10^{19} \mathrm{~cm}^{-3}\right)$, most likely due to oxygen donors. Details on their preparation have been reported elsewhere. ${ }^{20}$ The temperature of the samples was controlled via a closed-cycle refrigerator. The photoluminescence (PL) spectra were excited by three lasers: a $50 \mathrm{~mW} \mathrm{HeCd}$ laser at $3.814 \mathrm{eV}(3.814 \mathrm{eV})$ for above the band-gap excitation studies, an $\mathrm{Ar}^{+}$-ion laser with many discrete lines between 2.4 and $2.7 \mathrm{eV}$, and a Coumarin 540 dye laser with a tunable output between 2.1 and $2.35 \mathrm{eV}$. The PL signal was analyzed with a SPEX double spectrometer and detected with a cooled GaAs photomultiplier tube connected to a photon-counting system.

The above-band-gap-excited PL showed band-edge emission around 3.4-3.5 eV, as well as a strong YL peak centered around $2.25 \mathrm{eV}$. When the samples are excited by photons with energy below the band gap, the YL intensity decreases considerably and its line shape also changes significantly. The insets of Figs. 1(a) and 1(b) show, respec- 


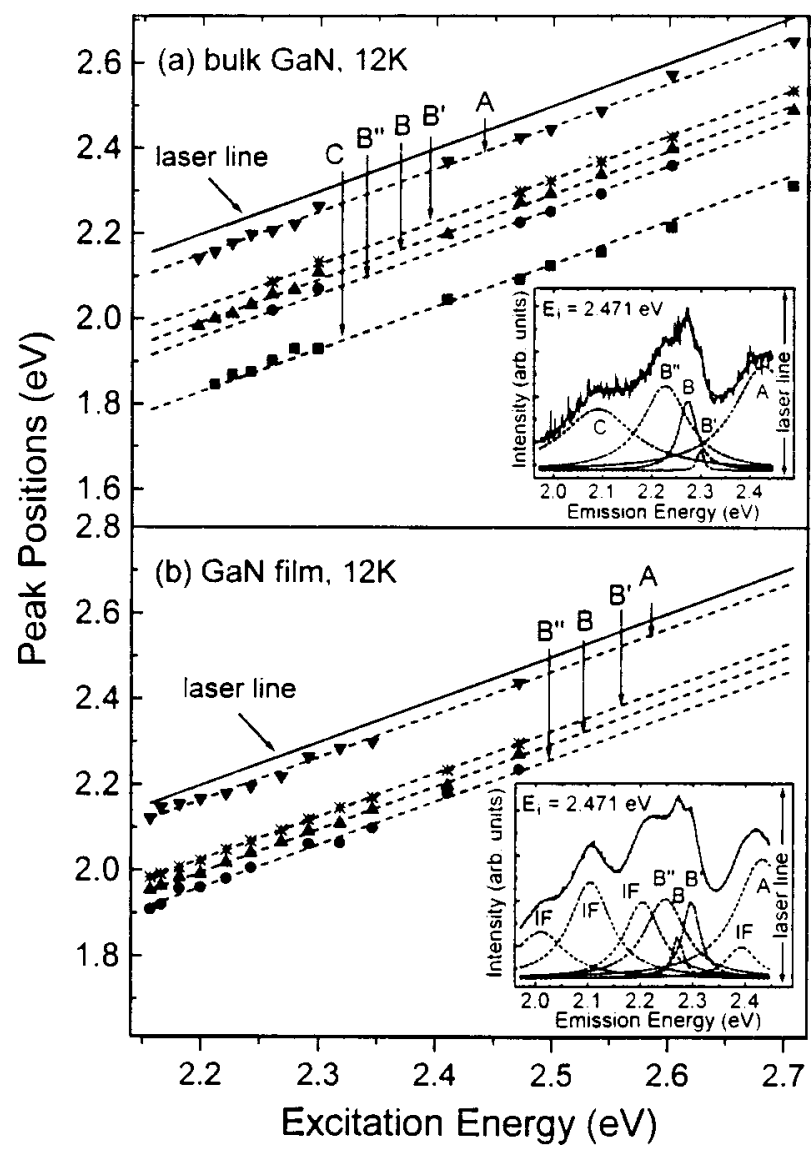

FIG. 1. Summary of the emission peak energies observed in the $12 \mathrm{~K}$ (PL) spectra of (a) a bulk GaN sample and (b) a GaN film, when excited between 2.2 and $2.7 \mathrm{eV}$. Inset: examples of typical below band-gap PL spectra in both bulk and thin film GaN (excited at $2.471 \mathrm{eV}$ ). The broken curves represent a deconvolution of the experimental (solid curve) spectrum into a sum of Lorentzians. The peaks labeled "IF" in the inset of (b) are caused by interference fringes and are not plotted in the peak energy summary.

tively, the PL of a bulk and thin film sample for a typical below the band-gap excitation ( $2.471 \mathrm{eV}$ in both cases), at 12 K. Several peaks are now observable instead of one broadband. By deconvoluting the PL spectra into a sum of Lorentzians, we have extracted the positions of several peaks which contribute to the PL. These peaks (labeled as A, B', B, B", and $\mathrm{C}$ ), are shown as the broken curves in the insets of Fig. 1. The second bulk sample displays similar results, except the finer structures in peak B are not resolved. The deconvolution process in the thin film sample is complicated by the presence of interference fringes [labeled as IF in Fig. 1(b) inset]. We have been able to distinguish these fringes from the YL peaks by noting that the IF peak energies do not change with excitation photon energy, $E_{i}$, while the YL peak energies vary linearly with $E_{i}$. The dependence of peaks $\mathrm{A}, \mathrm{B}$, on $E_{i}$ etc., is plotted in Fig. 1(a), for the bulk $\mathrm{GaN}$ sample, and Fig. 1(b), for the film. The similarities in these results for GaN samples grown by two completely different methods is a strong indication that similar defects are involved in their emission.

Note that the fine structures' energies, $E_{\mathrm{YL}}$, "follow" the excitation photon energy $E_{i}$, so that $E_{i}-E_{\mathrm{YL}}$ $=$ constant. The values of $E_{i}-E_{\mathrm{YL}}$ for peaks $\mathrm{A}, \mathrm{B}^{\prime}, \mathrm{B}, \mathrm{B}^{\prime \prime}$, and $\mathrm{C}$ in Fig. 1(a) are, respectively, 40, 170, 200, 240, and $370 \mathrm{meV}( \pm 10 \mathrm{meV})$. The energies determined from both

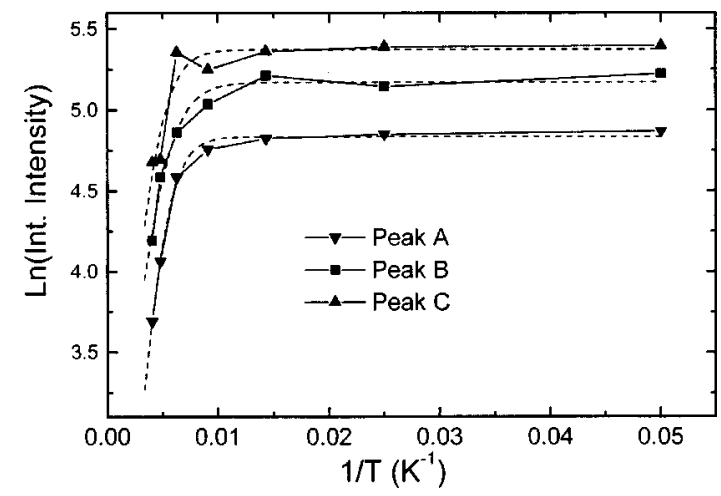

FIG. 2. Arrhenius plot of the temperature dependence of the PL intensity of peaks $\mathrm{A}, \mathrm{B}$, and $\mathrm{C}$ in the second bulk sample, with fit (dashed curves).

Figs. 1(a) and 1(b) agree within experimental uncertainties. In the second bulk sample (not shown), peak A has a slightly larger energy separation, $50 \pm 10 \mathrm{meV}$.

Peaks $\mathrm{A}, \mathrm{B}$, and $\mathrm{C}$ in the bulk samples show strong thermal quenching effects as shown by the Arrhenius plot in Fig. 2. Similar effects are more difficult to observe in the thin film sample because of the sensitivity of the interference fringes to temperature change. In addition to thermal quenching, all the peaks exhibit broadening so that the fine structures are difficult to discern at room temperature. Note that these results contrast with published above-the-gap excitation of the YL, which displays little dependence on temperature. $^{13,21}$ The data can be fit with the formula: $I$ $=I_{0} / 1+\alpha e^{\left(-E^{*} / k_{B} T\right)}$, with three adjustable parameters: $I_{0}$, $\alpha$, and $E^{*}$ (a thermal activation energy). The fitted $E^{*} \mathrm{~s}$ for peaks $\mathrm{A}, \mathrm{B}$, and $\mathrm{C}$, are respectively 67,65 , and $73 \mathrm{meV}$ $( \pm 10 \mathrm{meV})$.

In trying to explain our data we find these three features noteworthy: (1) given the high donor concentrations in our samples (above the Mott critical density), the electrons should be free and one might wonder why the YL exhibits any narrowing; (2) the selectively excited peaks still have a rather large amount of broadening (presumably homogeneous, $\sim 0.1 \mathrm{eV}$ ); and (3) the temperature dependence of the YL depends on if it is excited resonantly.

Spectral narrowing of DAP emission has been observed in $\mathrm{ZnSe}^{15}$ and $\mathrm{CdSe}^{16}$ by exciting donors and acceptors within a narrow range of spatial separation. However, in degenerate $n$-type samples, such as the GaN used in our study, the electrons are free and therefore can recombine with all photoexcited holes localized at the acceptors. As a result, the emission process would not necessarily involve the same donor as in the absorption process, and there would be no sharpening of the YL when selectively excited. However, some theories ${ }^{6,22}$ and experiments ${ }^{14,23}$ have suggested that the $\mathrm{YL}$ of $\mathrm{GaN}$ originates from complexes, or clusters, of shallow donor and deep acceptor pairs rather than from uncorrelated pairs. Thus, the selectively excited YL with width of $\sim 0.1 \mathrm{eV}$ we observe at low temperatures most likely originates from electrons and holes trapped at such DAP complexes.

The observation of peaks following the excitation line implies the existence of a continuous or quasi-continuous density of states (DOS). With DAP emission in the $\mathrm{ZnSe}$ and CdSe, for example, such a DOS exists due to the variations 
in the spatial separation between donor and acceptor. In a DAP complex, such a DOS could arise from fluctuation in energy levels due to variations in the distance or arrangement between the donor and acceptor, or from variations in the surroundings. Neugebauer and Van de Walle, ${ }^{6}$ for instance, note that the inhomogeneous broadening of such defect complexes may be large since defect levels can be broadened and shifted when the complexes are located near extended defects. The remaining homogeneous broadening of $\sim 0.1 \mathrm{eV}$ we observe has to be attributed to a strong electron-phonon interaction which is often present in such localized complexes. Although electron-phonon interaction has been used to explain the entire low temperature linewidth of $\mathrm{YL},{ }^{13}$ our results suggest that only $\sim 0.1 \mathrm{eV}$ out of a total width of $\sim 0.5 \mathrm{eV}$ is due to electron-phonon interaction.

To explain the different temperature dependence between the selectively excited and above-band-gap-excited $\mathrm{YL}$, we suggest that in addition to recombination between the donor-acceptor complexes, there is also recombination between distant DAPs (distant pairs). Thus, in our model, there are two separate recombination channels: DAP complexes, which would be favored by below the band-gap excitation, and distant DAPs, which would be favored when the sample is highly doped and when excited by above the bandgap excitation. ${ }^{24}$ The distant pairs recombination is expected to be dominant in above-band-gap excitation because of the large number of photoexcited free electrons. The concentration of these free electrons is not expected to be strongly dependent on temperature. On the other hand, the electrons involved in recombination from the DAP complexes are localized, and the activation energies of around $57-73 \mathrm{meV}$ probably represent the depth of traps localizing these electrons, since it is higher than the binding energy of electrons to isolated donors. At low temperatures and excited weakly by selective excitation, only electrons trapped at the DAP complexes are excited. But as temperatures increase, electrons can escape from the complexes, resulting in higher probability for nonradiative recombination and leading to the observed thermal quenching of the YL peaks. This explanation can reconcile various experiments which seem to lead to contradictory conclusions. For example, one group has observed a blue shift of the YL peak with an increase in excitation power, and has therefore concluded that the YL involves recombination of distant DAPs. ${ }^{13}$ On the other hand, another group has reported a correlation between the strength of YL and density of extended defects, leading to the conclusion that the YL involves DAP complexes. ${ }^{14}$ Within our model, it is possible to understand how in, certain circumstances, the DAP complex channel may become significant.

To identify the origin of peaks A, B, and C, we note that the emission may be shifted in energy from the excitation photons if (a) a phonon is emitted during the excitation or recombination process, or (b) the complex is photoexcited into a higher energy electronic state, followed by relaxation into the ground state before emission. The former process most likely accounts for the peak A. We note that substitutional $\mathrm{Si}_{\mathrm{Ga}}$ and $\mathrm{O}_{\mathrm{N}}$ donors are both lighter than the host atoms they replace, and therefore can produce localized phonons known as "gap modes." ${ }^{25}$ Indeed, the energy shift of $\sim 40 \mathrm{meV}$ for this peak lies in the gap between the acoustic and optical phonon branches in $\mathrm{GaN},{ }^{26}$ and is where gap modes are expected. The peaks $\mathrm{B}$ and $\mathrm{C}$, however, have much higher energy shifts than expected for phonon modes; therefore, we have tentatively attributed them to excited electronic states of the donor-acceptor complexes.

In conclusion, we have observed fine structures and strong thermal quenching in selectively excited $\mathrm{YL}$ of $\mathrm{GaN}$ samples. Our results suggest that in addition to distant pairs, the YL can also involve emission occurring at complexes of shallow donors and deep acceptors.

The work at Berkeley was supported by the Director, Office of Energy Research, Office of Basic Energy Sciences, Materials Sciences Division, of the U.S. Department of Energy under Contract No. DE-AC03-76SF00098.

${ }^{1}$ See, for example, S. Nakamura and G. Fasol, The Blue Laser Diode (Springer, New York, 1997).

${ }^{2}$ S. Nakamura, M. Senoh, S. Nagahama, N. Iwasa, T. Yamada, T. Matsushita, H. Kiyoku, Y. Sugimoto, T. Kozaki, H. Umemoto, M. Sano, and K. Chocho, Jpn. J. Appl. Phys., Part 2 36, L1568 (1997).

${ }^{3}$ S. Nakamura, Science 281, 956 (1998).

${ }^{4}$ T. Ogino and M. Aoki, Jpn. J. Appl. Phys., Part 1 19, 2395 (1980).

${ }^{5}$ P. Perlin, T. Suski, H. Teisseyre, M. Leszczynski, I. Grzegory, J. Jun, S. Porowski, P. Boguslawski, J. Bernholc, J. C. Chervin, A. Polian, and T. D. Moustakas, Phys. Rev. Lett. 75, 296 (1995).

${ }^{6}$ J. Neugebauer and C. G. Van de Walle, Appl. Phys. Lett. 69, 503 (1996).

${ }^{7}$ H. M. Chen, Y. F. Chen, M. C. Lee, and M. S. Feng, Phys. Rev. B 56, 6942 (1997).

${ }^{8}$ K. Saarinen, T. Laine, S. Kuisma, J. Nissilä, P. Hautojärvi, L. Dobrzynski, J. M. Baranowski, K. Pakula, R. Stepniewski, M. Wojdak, A. Wysmolek, T. Suski, M. Leszczynski, I. Grzegory, and S. Porowski, Phys. Rev. Lett. 79, 3030 (1997)

${ }^{9}$ W. G. Perry, M. B. Bremser, and R. F. Davis, J. Appl. Phys. 83, 469 (1998).

${ }^{10}$ D. M. Hofmann, D. Kovalev, G. Steude, B. K. Meyer, A. Hoffmann, L. Eckey, R. Heitz, T. Detchprom, H. Amano, and I. Akasaki, Phys. Rev. B 52, 16702 (1995).

${ }^{11}$ C. V. Reddy, K. Balakrishnan, H. Okumura, and S. Yoshida, Appl. Phys. Lett. 73, 244 (1998).

${ }^{12}$ E. R. Glaser, T. A. Kennedy, K. Doverspike, L. B. Rowland, D. K. Gaskill, J. A. Freitas, Jr., M. Asif Khan, D. T. Olson, J. N. Kuznia, D. K. Wickenden, Phys. Rev. B 51, 13326 (1995).

${ }^{13}$ U. Kaufmann, M. Kunzer, H. Obloh, M. Maier, Ch. Manz, A. Ramakrishnan, and B. Santic, Phys. Rev. B 59, 5561 (1999).

${ }^{14}$ G. Li, S. J. Chua, S. J. Xu, W. Wang, P. Li, B. Beaumont, and P. Gibart, Appl. Phys. Lett. 74, 2821 (1999).

${ }^{15}$ H. Tews, H. Venghaus, and P. J. Dean, Phys. Rev. B 23, 4097 (1981).

${ }^{16}$ P. Y. Yu and C. Hermann, Phys. Rev. B 23, 4097 (1981).

${ }^{17}$ M. Rosenbauer, S. Finkbeiner, E. Bustarret, J. Weber, and M. Stutzmann, Phys. Rev. B 51, 10539 (1995).

${ }^{18}$ A. Saito and T. Suemoto, Phys. Rev. B 56, R1688 (1997).

${ }^{19}$ N. Wieser, O. Ambacher, H.-P. Felsl, L. Görgens, and M. Stutzmann, Appl. Phys. Lett. 74, 3981 (1999).

${ }^{20} \mathrm{~S}$. Porowski and I. Grzegory, in GaN and Related Materials, edited by J. Pearton, Optoelectronic Properties of Semiconductors and Superlattices (Gordon and Breach, Amsterdam, 1997), Vol. 2, p. 295.

${ }^{21}$ R. Zhang and T. F. Kuech, Appl. Phys. Lett. 72, 1611 (1998).

${ }^{22}$ T. Mattila and R. M. Nieminen, Phys. Rev. B 55, 9571 (1997).

${ }^{23}$ F. A. Ponce, D. P. Bour, W. Götz, and P. J. Wright, Appl. Phys. Lett. 68, 57 (1996).

${ }^{24}$ More detail provided in J. S. Colton, P. Y. Yu, K. L. Teo, P. Perlin, E. R. Weber, I. Grzegory, and K. Uchida, Physica B (to be published) (ICDS-20 Proceedings).

${ }^{25}$ A. S. Barker, Jr., and A. J. Sievers, Rev. Mod. Phys. 47, Suppl. 2, S1 (1975).

${ }^{26}$ J. C. Nipko, C.-K. Loong, C. M. Balkas, and R. F. Davis, Appl. Phys. Lett. 73, 34 (1998). 